\title{
The effects of size of opening in vegetation and litter cover on seedling establishment of goldenrods (Solidago spp.)
}

\author{
Deborah E. Goldberg and Patricia A. Werner \\ W.K. Kellogg Biological Station and Department of Botany and Plant Pathology, Michigan State University, \\ Hickory Corners, MI 49060, USA
}

\begin{abstract}
We investigated the effects of size of opening in the vegetation and litter cover on seedling establishment of two species of goldenrods (Solidago spp.) in an abandoned field in southwestern Michigan, U.S.A. Seeds of $S$. canadensis and $S$. juncea were sown into clipped plots, ranging from $0 \mathrm{~cm}$ (control, unclipped) to $100 \mathrm{~cm}$ in diameter, with and without litter. Seedling emergence, survival and growth were followed for one year. Soil moisture was not significantly different among the opening sizes, but, within a size, tended to be lower when litter was removed. Light intensity at the soil surface was positively related to opening size early in the growing season, but later in the growing season reached a maximum in intermediate-sized openings and then leveled off.

Litter strongly inhibited seedling emergence in both species. Emergence of $S$. canadensis seedlings was lower in 0 and $10 \mathrm{~cm}$ openings than in the larger openings, while emergence of $S$. juncea seedlings was lower in the largest openings $(100 \mathrm{~cm})$ than in all the smaller openings. In contrast, seedling growth and probability of survival increased with diameter of opening for both species. Some seedlings of $S$. juncea did survive in complete vegetation cover (controls, $0 \mathrm{~cm}$ openings) while seedlings of $S$. canadensis survived only in openings of at least $30 \mathrm{~cm}$ diameter. Thus, $S$. juncea had a smaller minimum opening size for seedling establishment than $S$. canadensis, although both species grew and survived best in the largest openings made in the experiment.
\end{abstract}

\section{Introduction}

Many, if not most, plant species seem to require an opening in established vegetation for successful recruitment of new seedlings (eg. Sagar and Harper 1961; Tamm 1956; Litav et al. 1963; Cavers and Harper 1967; Miles 1972; Summerfield 1973; Putwain and Harper 1970; McMahon and Ungar 1978; Gross 1980; Peart 1984; but see Gross and Werner 1982). Attention is therefore becoming focused on the qualities of openings that affect regeneration by seed and on comparisons among species in their responses to these qualities (Grubb 1977; Fenner 1978; Gross and Werner 1982). Openings in vegetation may be created by

Present address and offprint requests to: D.E. Goldberg, Division of Biological Sciences, University of Michigan, Ann Arbor, MI 48104, USA many factors, including disturbance by animals, frost heaving, and death of individual plants or groups of plants. One of the most important qualities of openings that affects seedling germination, growth and survival may be size (Davis and Cantlon 1969; Ross and Harper 1972; Ehrenfeld 1980; Runkle 1982). Is there a continuous increase in probability of establishment with increasing size of opening or is there an intermediate size of opening at which establishment is maximal? Because the distribution of openings of various sizes may be related to factors such as soil type or size of mature plants, answers to this question may help explain species distributions, both within and among communities.

We examined the effect of opening size as well as removal of litter cover on seedling establishment in two species of goldenrod, Solidago canadensis L. var scabra (Muhl.) T.I.G. and S. juncea Ait. (See Werner et al. 1980 for a discussion of the taxonomy of $S$. canadensis). Both are perennial, rhizomatous herbs common in natural grasslands and mid to late successional abandoned-fields in the northeastern United States. In a successional sere these species have similar temporal distributions: both usually appear during the first five years or so after abandonment of a field and increase in biomass until woody vegetation becomes dominant. However, they have different spatial distributions within fields (Werner and Platt 1976). Solidago canadensis is most abundant in mesic areas with relatively high total vegetation cover, biomass, and height, while $S$. juncea occurs in drier areas with lower vegetation cover, biomass and height.

In this study, we focused on whether differential seedling establishment in the mesic area is responsible for the difference in distribution of the two species. We hypothesized that seedlings of $S$. juncea are poorer competitors than $S$. canadensis in the tall, closed vegetation characteristic of mesic areas and hence unable to establish, while S. canadensis seedlings are able to establish. Alternatively, both species may require some sort of disturbance to establish in mesic areas, but $S$. juncea may require a larger opening than $S$. canadensis. Because one of the most common types of disturbance in old-field communities is caused by animal burrowing, which removes litter as well as vegetation cover, we examined the effect of removal of litter as well as variation in opening size on seedling establishment. Animal burrowing also disturbs the soil; however we decided to evaluate the effects of vegetation (both living and dead material) independently of any changes in soil structure caused by a disturbance. 


\section{Methods}

Site. The experiments were conducted in Louden Field, abandoned from pasturage 30 years prior to this study (Stergios 1970) at the Kellogg Biological Station in Kalamazoo County in southwestern Michigan, USA. The experimental site was in a relatively mesic part of the field with close to $100 \%$ plant cover. The dominant species (all perennial herbs) were Solidago canadensis, $S$. graminifolia, Bromus inermis, and Trifolium repens. No $S$. juncea plants were found in the area. Vegetation height at the end of June was $72 \pm 2 \mathrm{~cm}$. The litter was composed primarily of horizontal goldenrod and grass stems. Mean litter depth (top of litter to mineral soil surface) at the end of June was $3.14 \pm 0.27 \mathrm{~cm}$.

Openings. Five different sizes of openings $(0,10,30,50$, and $100 \mathrm{~cm}$ in diameter) were made in May 1981 by clipping all plants within the designated area at ground level. The $0 \mathrm{~cm}$ openings (controls) were probably not a distinct treatment from the $10 \mathrm{~cm}$ diameter openings because interstem distances were between 5 and $10 \mathrm{~cm}$ in undisturbed vegetation. Removal of plants by clipping has the advantage of not disturbing the soil surface but the disadvantage of leaving roots in the soil which may decay and contribute nutrients (Newbery 1979) or which may resprout and hence continue to withdraw nutrients and water from the soil. The latter problem was mitigated by continued reclipping throughout the summer at approximately biweekly intervals during the early part of the growing season (May-June) and at monthly intervals through September. The plots were not reclipped during the second growing season (1982).

For each of the two species, 10 replicates of each opening size were made leaving all litter intact and another 10 replicates were made removing all litter. The replicates were laid out in a randomized design along transects with at least $1 \mathrm{~m}$ between the edges of adjacent plots.

Planting. Seeds of both species were collected the fall of 1980 , stored at room temperature all winter, and planted on June 1, 1981. Because the parameter of interest was distance of seedlings to established vegetation (radius of opening), only an area $5 \mathrm{~cm}$ in diameter in the center of each plot was planted, regardless of size of opening. Approximately 2000 seeds of the appropriate species were placed on the soil surface in each plot. In the plots with litter, seeds were placed under the litter layer.

Seedlings began to emerge within 17-21 days and emergence was virtually complete by June 31 . All goldenrod seedlings growing in the central $10 \mathrm{~cm}$ of a plot were marked with plastic toothpicks as they emerged, and censused for survival and growth at ten-day intervals throughout the growing season of 1981 (June-September) and then again in July 1982. Background germination was very low - almost no goldenrod seedlings of either species were observed outside a central area $10 \mathrm{~cm}$ in diameter in each plot.

Soil moisture. Percent soil moisture in each treatment was measured gravimetrically in samples taken from $2-5 \mathrm{~cm}$ depth at three dates during the 1981 growing season. A soil sample was taken from the center of each of five replicate plots of each treatment. In order not to disturb seed- lings growing in the experimental plots, the soil moisture samples were taken from additional replicates of the treatments without seeds planted or, later, from plots in which no seedlings germinated or survived. All samples were taken 3-4 days after a sequence of rainy days with a total accumulation of at least $1.7 \mathrm{~cm}$.

Light. An estimate of light availability at the soil surface in a subsample of the experimental plots was determined in June and September 1981. Light intensity was measured in the center of a plot at the soil surface (under litter, if present) and above the vegetation surrounding the opening (full sunlight) and the data presented as \% of full sunlight. All readings were taken between 1100 and $1400 \mathrm{~h}$ eastern standard time. There were 8 readings per treatment in June and 7-15 readings per treatment in September. The June readings were taken with a Weston Illuminator and light intensity was measured in lux. The September readings were taken with a LI-COR photometer and measured in microeinsteins $/ \mathrm{m}^{2} / \mathrm{sec}$.

Analysis. Because the number of seeds planted per plot (ca. 2000) far exceeded the number of seedlings emerging in each plot (maximum $=58$ ), we have assumed that any differences in emergence rate were not due to variation in number of seeds planted. Seedling emergence was very variable in these plots; all treatments contained some replicates in which no seedlings emerged. As a result, numbers of seedlings at all censuses were not normally distributed and variances were significantly heterogeneous even after square root transformations. Therefore, all analyses on numbers and survival of seedlings were done on the totals summed over all replicates within a treatment. Chi square goodnessof-fit tests were used to analyze numbers of seedlings at emergence and after 1 year. The expected numbers of seedlings in each treatment were based on an even distribution among all treatments. Chi square contingency tables were used to analyze percentage survival of seedlings: the number of emerged seedlings which survived one year vs. the number which died in each treatment were compared. To compare individual treatments, $2 \times 2$ Chi square tests were used, but only pairs of treatments significant at the 0.005 level were considered as significantly different. Expected values were calculated in the same way as in the overall chi square tests. We decided on this conservative test to allow for the distortion of $\alpha$ levels due to the multiple pairwise comparisons (Conover 1980).

\section{Results}

The presence of litter strongly inhibited seedling emergence in both species (Fig. 1). Summing over the opening size treatments, the chi square values for both species were highly significant ( 99.436 and 128.39 for $S$. canadensis and $S$. juncea, respectively, d.f. $=1, P \ll 0.001$ for both tests). Because so few seedlings emerged in the presence of litter (totals of 9 for $S$. canadensis and 38 for $S$. juncea), no effects of opening size with litter present could be evaluated for either emergence or subsequent survival. Therefore all subsequent analyses are for the litter-removed treatments only.

Opening size significantly affected emergence of both species (Table 1), although the pattern of differences among treatments was not the same between the species. Emer- 
gence of $S$. canadensis seedlings was significantly lower in the two smallest openings $(0,10 \mathrm{~cm})$ than in the openings at least $30 \mathrm{~cm}$ in diameter. Emergence of $S$. juncea seedlings was significantly lower in the largest opening $(100 \mathrm{~cm})$ and there were not significant differences among the smaller openings. The single largest number of emerging seedlings for both species was in the intermediate-sized plots $(30 \mathrm{~cm})$.

Percent survival of emerged seedlings into the second growing season showed a different pattern than that for emergence: survival of both species increased with opening size, although the overall chi square was significant only for $S$. canadensis which had a very abrupt increase in survival between the $50 \mathrm{~cm}$ and $100 \mathrm{~cm}$ treatments (Table 1). The more gradual increase in survival with diameter of opening for $S$. juncea yielded no significant opening size effects in a chi square test (Table 1).

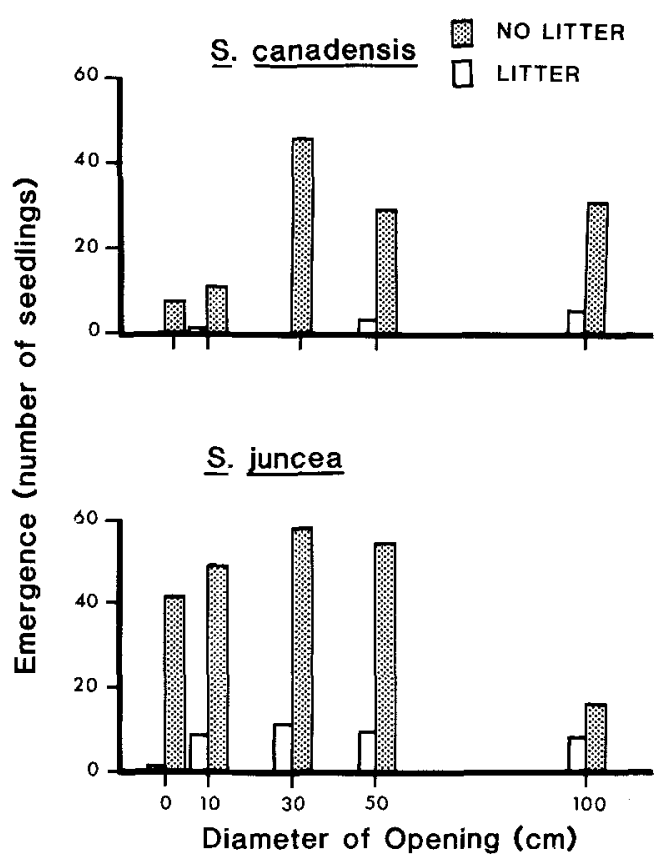

Fig. 1. Total number of seedlings of $S$. canadensis and $S$. juncea which emerged in openings of different sizes, with and without litter present. Only seedlings in a $10 \mathrm{~cm}$ diameter area in the center of each plot were counted
Because both emergence and probability of survival increased with opening size for $S$. canadensis, after one year this species had a significantly greater number of seedlings in the largest openings (Table 1, Fig. 2). However, for $S$. juncea the negative effect of opening size on emergence combined with the positive trend for survival resulted in no significant pairwise differences between treatments in numbers of seedlings in the second growing season, although the overall chi square was significant (Table 1). The combination of the effects of opening size on emergence and on survival are shown clearly in the survivorship curves in Fig. 2. After one year, the high rate of survivorship of $S$. juncea in the $100 \mathrm{~cm}$ plots had not yet compensated for the low emergence in those plots.

There was no evidence of any density dependent interactions among seedlings: within a given treatment there were

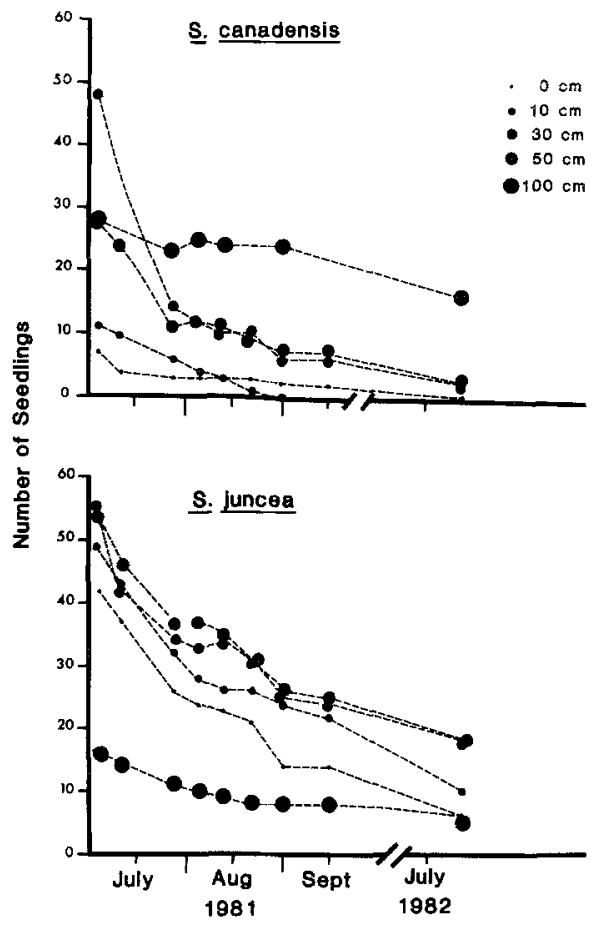

Fig. 2. Seedling survival in openings of different sizes with litter removed. Values are total number of seedlings alive in all plots of each treatment

Table 1. Emergence and survival of seedlings in different size openings in litter-removed plots. Values within a row with the same letter are not significantly different in pairwise $\chi^{2}$ tests, using $P<0.005$ as a conservative significance level for the pairwise comparisons

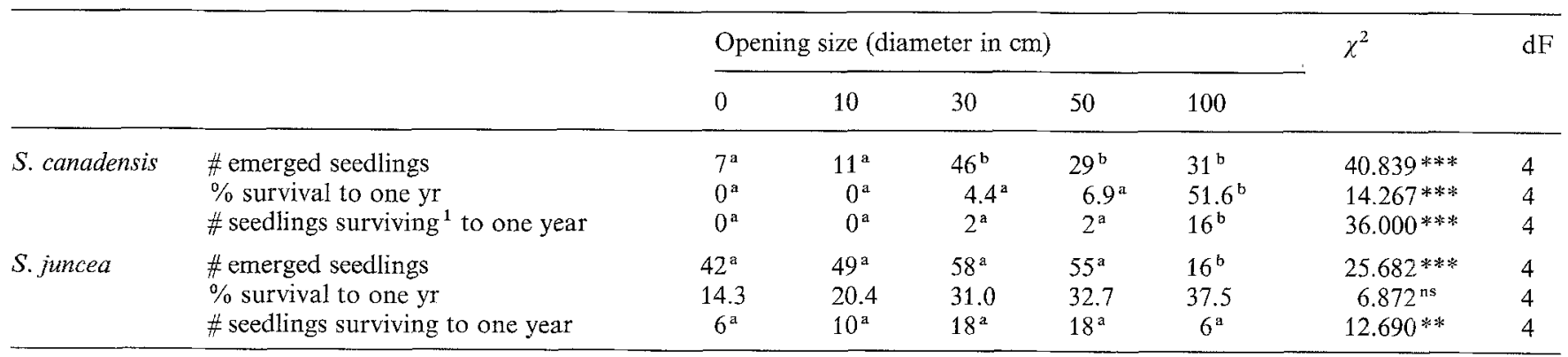

ns $P>0.05, * * P<0.01, * * * P<0.001$

1 expected values in each treatment all less than 5 
Table 2. Seedling growth in different size openings in the litter-removed plots. Values are means and end points of the $95 \%$ confidence interval in parentheses. Data were log transformed prior to a one-way analysis of variance and then backtransformed for presentation. The extremely large confidence intervals for $S$. canadensis seedlings after 13 months of growth are because of the few surviving seedlings $(n=2)$, rather than larger variances on that date. Height was measured only for $S$. canadensis after 13 mo of growth when seedlings had assumed the vertical growth form typical of adults. $S$. juncea seedlings remained as rosettes in their second year of growth. Values within a row with the same letter are not significantly different at the 0.05 level by an SNK test (Sokal and Rohlf 1969). No comparison of means was made if the ANOVA was not significant

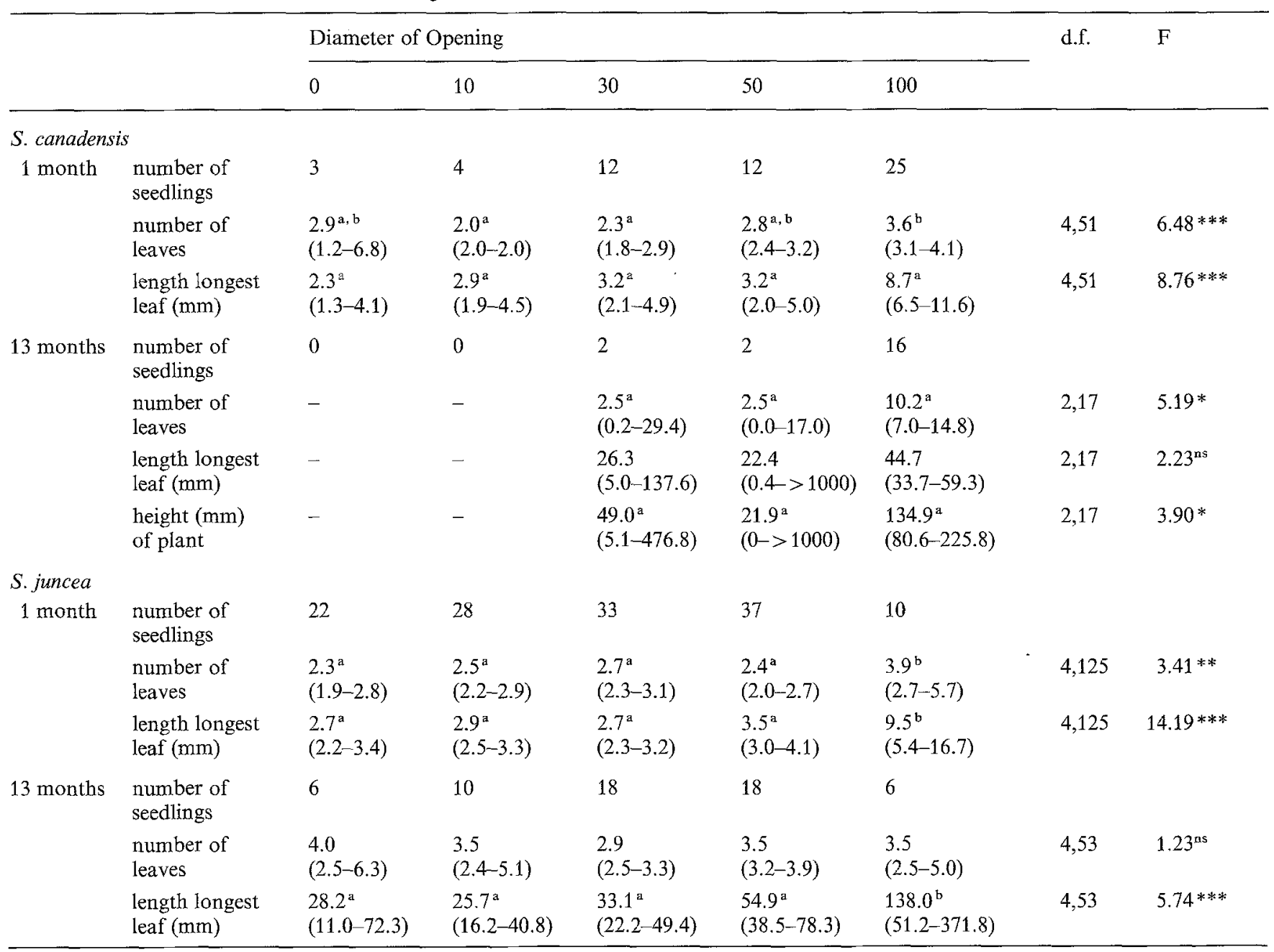

${ }^{\mathrm{ns}} P>0.05, * P<0.05, * * P<0.01, * * * P<0.001$

no significant rank correlations between percent survival and initial numbers of seedlings within a plot.

The patterns of seedling growth are very similar to those for percent survival (Table 2). One month after planting, mean number of leaves per seedling and length of longest leaf were significantly affected by opening size in both species. For both these measures of plant size, the largest seedlings were in the largest openings $(100 \mathrm{~cm})$, and in all cases but number of leaves for $S$. canadensis, pairwise comparisons of opening sizes through $50 \mathrm{~cm}$ were not significant, while seedlings in $100 \mathrm{~cm}$ openings were significantly larger than those in all the smaller openings. Similar trends are seen after 13 months of growth, although the species began to differ in the parameters in which they responded to opening size (Table 2). Solidago canadensis seedlings were largest in the $100 \mathrm{~cm}$ openings in all parameters measured, with the strongest response in plant height, although none of the pairwise treatment comparisons was significant (probably due to the small number of seedlings surviving to 13 months). Solidago juncea responded in length of leaves, but not in number of leaves.

To provide possible explanations for the patterns of seedling emergence, survival and growth as a function of litter cover and opening size, we analyzed the differences in soil moisture and light availability in these treatments.

No significant effect of size of opening on $\%$ of soil moisture below the soil surface was detected on any date (Fig. 3). The presence of litter significantly increased subsurface soil moisture on one of the three dates sampled during the 1981 growing season (Fig. 3). Light availability early in the growing season increased from the smallest to the largest openings, where it reached $98 \%$ full sunlight in the absence of litter (Fig. 4). Later in the growing season, light availability reached a maximum of $25 \%$ full sunlight in the $30 \mathrm{~cm}$ openings but was not any greater in the larger openings. In the plots with litter present, light levels at the soil surface were much lower than in the same size openings with litter removed and the difference between 

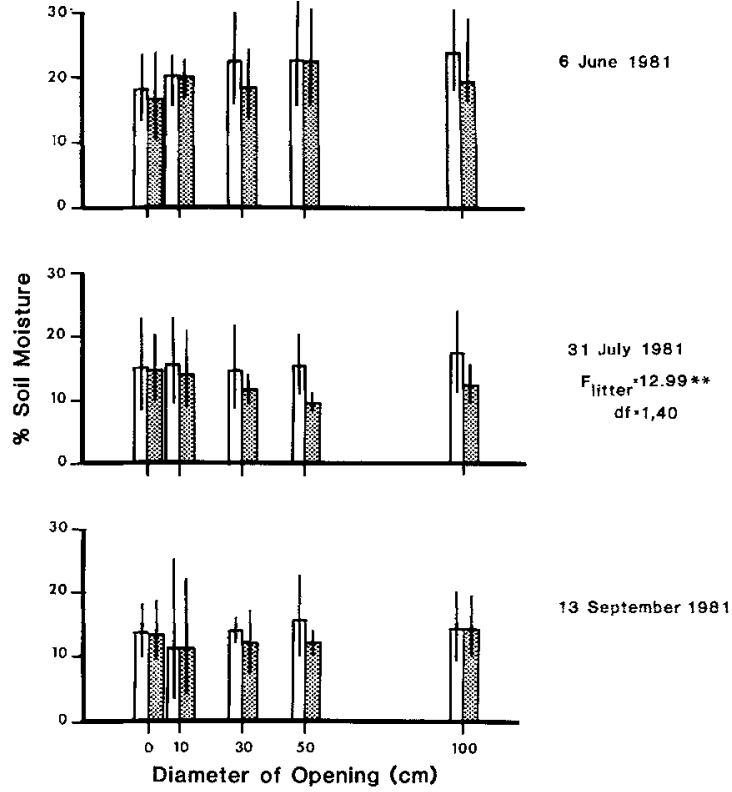

Fig. 3. Percent soil moisture at three dates during the 1981 growing season. Data were subjected to an angular transformation prior to analysis and backtransformed for presentation. The height of each histogram represents the mean of 5 samples and vertical bars represent $95 \%$ confidence intervals. Only significant $(P<0.05) \mathrm{F}$ values from a two-way ANOVA (litter $\times$ opening diameter) are shown. "**" indicates $P<0.01$

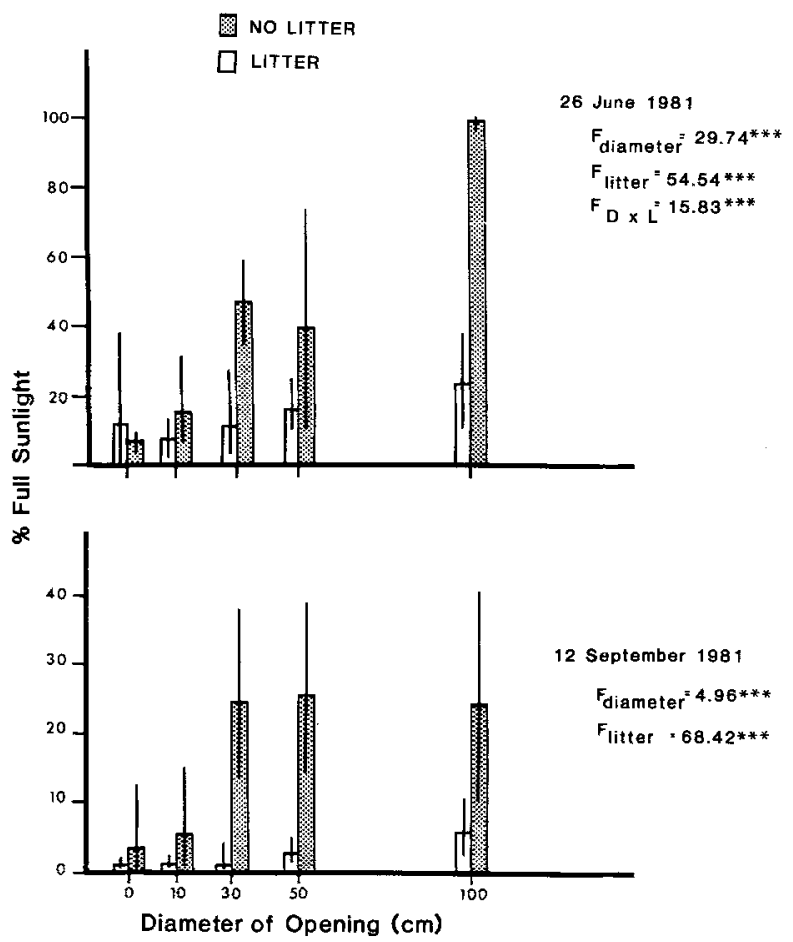

Fig. 4. Percent of full sunlight measured at the soil surface at two dates during the 1981 growing season. Data were subjected to an angular transformation prior to analysis and backtransformed for presentation. The height of the histograms represents the mean of either 8 samples (June measurements) or 7-15 samples (August measurements). Vertical bars are $95 \%$ confidence intervals. Only significant $(P<0.05) \mathrm{F}$ values from a two-way ANOVA (litter $\times$ opening diameter) are shown. *** indicates $P<0.001$ litter-present and litter-removed plots increased with opening size, resulting in a significant size $\times$ litter interaction in the ANOVA (Fig. 4).

\section{Discussion}

The discussion touches on several points: the mechanisms producing the observed patterns in seedling emergence, survival and growth; the implications for the spatial distribution of the two species relative to soil moisture within old fields, and the implications for the temporal appearance of $S$. canadensis and $S$. juncea in the successional sequence in abandoned field communities.

\section{Mechanisms}

Emergence. The low emergence of both species under litter could be due to several factors, such as low light availability under litter (cf. Fig. 4), high early mortality due to mechanical impedance by litter or due to fungal infection in the dark, moist conditions under litter, or chemical inhibition resulting from some substance produced by the litter. Although we have no direct evidence bearing on which factor is most important, the low emergence of $S$. canadensis in all opening sizes with litter present and also in openings of 0 and $10 \mathrm{~cm}$ with litter removed is consistent with inhibition of emergence by low light levels. For $S$. juncea, however, the emergence patterns are not completely explainable by the light conditions. The 0 and $10 \mathrm{~cm}$ openings with litter removed had lower light levels than openings $30 \mathrm{~cm}$ or larger, but emergence was not significantly reduced relative to the larger openings. The $100 \mathrm{~cm}$ openings with litter present had approximately the same light levels as the small openings with litter removed, but emergence was lower in the former. The cause of the low emergence of $S$. juncea in the largest openings is unclear.

Survival and growth. The effects of opening size on survival and growth of seedlings are most likely due to light. Both species had perfect rank correlations of percent survival with opening size (Table 1), although the actual relationship was gradual for $S$. juncea and more abrupt for $S$. canadensis. Both species showed much greater growth in the $100 \mathrm{~cm}$ openings than in the smaller openings. These results correspond with the increase in light availability from approximately $40 \%$ of full sunlight in the 30 and $50 \mathrm{~cm}$ openings to $98 \%$ of full sunlight in the $100 \mathrm{~cm}$ openings in the June measurements. The continued strong differences in growth even after one year, combined with the lack of difference in light among the 30,50 , and $100 \mathrm{~cm}$ openings late in the first growing season (August) suggest that conditions prevailing around the time of germination and in the first month of growth are more important in determining subsequent survival and growth rate than conditions later in the first season or in the subsequent season. This is further substantiated by the strong effects of opening size seen after 13 months of growth, despite the fact that the openings were not recleared after September 1981 and by the 13 month census in July, 1982, openings of all sizes had completely closed in and vegetation height within the openings did not appear to be different from that outside the openings (although the composition of the vegetation did differ). 


\section{Spatial Separation of species}

Although both species have their highest probability of survival and reach their largest individual size in the largest openings used in this experiment, they strongly differ in the minimum size of opening they require for any establishment at all. Seedlings of $S$. juncea survived to $1 \mathrm{yr}$ even in the controls ( $0 \mathrm{~cm}$ openings), albeit with low growth rate, while $S$. canadensis seedlings survived only in openings $30 \mathrm{~cm}$ or larger. For $S$. canadensis, even the 30 and $50 \mathrm{~cm}$ openings had extremely low survival $(<10 \%)$, so that establishment is far more likely in the largest openings, where survival was greater than $50 \%$. Using the minimum distance a seedling must be from established large plants (radius of smallest opening in which seedlings can survive) as a measure of competitive ability, $S$. juncea seedlings are better competitors than $S$. canadensis seedlings. The superior competitive ability of $S$. juncea may be due to its larger seed size $(27.3 \mu \mathrm{g}$ vs. $17.6 \mu \mathrm{g}$; Werner and Platt 1976). Several workers have found that seedlings from large seeds are better able to establish in closed vegetative cover than seedlings from small seeds, both in interspecific (Fenner 1978; Gross and Werner 1982; Gross 1984) and intraspecific comparisons (Stanton 1982; Gross 1984).

These results for seedlings experimentally sown in a mesic area of a $30 \mathrm{yr}$-old field contrast with those found for transplanted adult ramets of the same two species in the same site (Werner in prep.). Werner found that, in mesic areas, $S$. canadensis ramets could survive in the presence of competition, although they grew better when surrounding vegetation was removed, while $S$. juncea ramets survived only when surrounding vegetation was removed. Thus, at the same site (although in different years), $S$. canadensis was the superior adult competitor, while $S$. juncea was the superior seedling competitor. The reason for the switch in relative competitive abilities with age is probably due to a shift from predominance of seed size effects to predominance of growth form effects. Both species are horizontal rosettes in their first year, but $S$. juncea has larger seeds. In the adult stage $S$. canadensis has vertical ramets able to grow at least as tall as the surrounding vegetation, while $S$. juncea has horizontal rosettes which are shaded by the surrounding vegetation.

The adult relative competitive abilities correlate well with the observed distribution pattern of adult goldenrods: the better adult competitor is most abundant in mesic areas of fields where vegetation is taller and competition for light is relatively intense. The poorer adult competitor, $S$. juncea, is most abundant in relatively dry areas of fields where vegetation is short and competition for light is not very intense; it has a much greater tolerance of low soil moisture levels than does $S$. canadensis (Werner in prep.). The spatial distribution pattern is probably determined by differential mortality of growing, young adult plants, rather than differential success as first-year seedlings.

\section{Succession}

The results presented in this paper suggest that there is very little regeneration by new genets of $S$. canadensis in the field studied, despite the fact that it is a dominant component of the vegetation in the field. Openings as large as even $30 \mathrm{~cm}$ are almost nonexistent in mesic areas in this field (Gross and Goldberg, unpublished data) so that the chance of a seed landing (and remaining) in an opening large enough to allow survival is very small. It seems likely that the dominance of $S$. canadensis in this $30 \mathrm{yr}$-old field has been attained by vegetative ramification (ramet production) of genets established earlier in the successional sequence, when a much greater proportion of the field was bare ground. Even though $S$. juncea seedlings were relatively successful in establishing in small openings, Werner's experiments suggest that they would not survive to reproductive maturity in mesic areas. S. juncea may be regenerating in drier areas (where it is currently most abundant) where openings of all sizes are more common than in mesic areas (Gross and Goldberg unpublished data, cf. Platt and Weiss 1977).

Acknowledgements. We thank Jeff Waldeck, Penny Meints, and Jodi Seeley for assistance in the field and Katherine Gross, Craig Osenberg, and David Peart for their helpful comments on the manuscript. The research was supported by grants from the National Science Foundation, DEB-7923945 and DEB-8111315. W.K. Kellogg Biological Sation Contribution No. 509.

\section{References}

Cavers PB, Harper JL (1967) Studies in the dynamics of plant populations. I. The fate of seed and transplants introduced into various habitats. $J$ Ecol 55:59-71

Conover WJ (1980) Practical Nonparametric Statistics. John Wiley $\&$ Sons, New York

Cook RE (1979) Patterns of juvenile mortality and recruitment in plants. Topics in Plant Population Biology. OT Solbrig, S Jain GB Johnson, and PH Raven (eds) Columbia University Press, New York, pp 207-231

Davis RM, Cantlon JE (1969) Effect of size area open to colonization on species composition in early old-field succession. Bull Torr Bot Club 96:660-673

Ehrenfeld JG (1980) Understory response to gaps of varying size in a mature oak forest. Bull Torr Bot Club 107:29-41

Fenner M (1978) A comparison of the abilities of colonizers and closed-turf species to establish from seed in artificial swards. J Ecol 66:953-963

Gross KL (1980) Colonization of Verbascum thapsus (Mullein) in an old field in Michigan: The effects of vegetation. J Ecol 68:919-927

Gross KL (1984) Effects of seed size and growth form on seedling establishment of six monocarpic perennials. J Ecol:in review

Gross KL, Werner PA (1982) Colonizing abilities of "biennial" plant species in relation to ground cover: implications for their distributions in successional fields. Ecology 63:921-931

Grubb PJ (1977) The maintenance of species-richness in plant communities: The importance of the regeneration niche. Biol Rev $52: 107-145$

Litav M, Kupernik G, Orshan G (1963) The role of competition as a factor in determining the distribution of dwarf shrub communities in the Mediterranean territory of Israel. J Ecol $51: 467-480$

McMahon K, Ungar IA (1978) Phenology, distribution and survival of Atriplex triangularis Willd. in an Ohio salt pan. Amer Midl Natur 100:1-14

Miles J (1972) Experimental establishment of seedlings on a southern English heath. J Ecol 60:225-234

Newbery D McC (1979) The effects of decomposing roots on the growth of grassland plants. J Appl Ecol 16:613-622

Peart DR (1984) Experimental analysis of grassland succession. Ecol Monogr:in press

Platt WJ, Weis IM (1977) Resource partitioning and competition within a guild of fugitive prairie plants. Amer Natur $111: 479-513$

Putwain PD, Harper JL (1970) Studies in the dynamics of plant populations. III. The influence of associated species on pupula- 
tions of Rumex acetosa L. and $R$. acetosella L. in grassland. J Ecol 58:251-264

Ross MA, Harper JL (1972) Occupation of biological space during seedling establishment. J Ecol 60:77-88

Runkle JR (1982) Patterns of disturbance in some old-growth mesic forests of eastern North America. Ecology 63:1533-1546

Sagar GR, Harper JL (1961) Controlled interference with natural populations of Plantago lanceolata, $P$. major and $P$. media. Weed Res 1:163-176

Sokal RR, Rohlf FJ (1969) Biometry. W.H. Freeman and Co., San Francisco

Stanton M (1982) Ecological consequences of flower variation in the wild radish. Bull Ecol Soc Amer 63:129

Stergios BG (1970) Seed dispersal, seed germination, and seedling establishment of Hieracium auriantiacum in an old-field community. Ms. thesis, Michigan State University

Summerfield RJ (1973) Factors affecting the germination and seedling establishment of Narthecium ossifragum on mire ecosystems. J Ecol $61: 387-398$
Tamm CO (1956) Further observations on the survival and flowering of some perennial herbs. Oikos 7:274-292

Werner PA (1979) Competition and the coexistence of similar species. Topics in Plant Population Biology. OT Solbrig, S. Jain, GB Johnson, PH Raven (eds) Columbia University Press, N.Y., pp 287-310

Werner PA Plant distributions along environmental gradients: A field experimental analysis of the factors affecting goldenrods in virgin prairie and old-field habitats. Ecol Monogr (in preparation)

Werner PA, Platt WJ (1976) Ecological relationships of co-occurring goldenrods (Solidago: Compositae). Amer Natur 110:959-971

Werner PA, Bradbury IK, Gross RS (1980) The biology of Canadian weeds. 45. Solidago canadensis L. Can J Plant Sci $60: 1393-1409$

Received February 25, 1983 